\title{
Two-year outcomes after full-thickness astigmatic keratotomy combined with small-incision lenticule extraction for high astigmatism
}

\author{
Bu Ki Kim ${ }^{1}$ and Young Taek Chung ${ }^{2^{*}}$ (1)
}

\begin{abstract}
Background: To evaluate clinical outcomes after full-thickness astigmatic keratotomy (FTAK) combined with smallincision lenticule extraction (SMILE) in eyes with high astigmatism.

Methods: This study comprised 75 eyes of 43 patients with over 4.0 diopters (D) of astigmatism who were treated with SMILE after FTAK. Visual acuities and refractive measurements were evaluated at 1 month after FTAK, and 1, 6 , 12, and 24 months after SMILE. Vector analysis of the astigmatic changes was performed using the Alpins method.

Results: Twenty-four months after the combined procedure, the average spherical equivalent was reduced from $6.56 \pm 2.38 \mathrm{D}$ to $-0.36 \pm 0.42 \mathrm{D}(p<0.001)$. The uncorrected and corrected distance visual acuities improved from $1.54 \pm 5.53$ to $-0.02 \pm 0.09$ and from $-0.03 \pm 0.07 \mathrm{D}$ to $-0.07 \pm 0.08 \mathrm{D}$ (both $p<0.001$ ), respectively. The preoperative mean astigmatism was $-5.48 \pm 1.17 \mathrm{D}$, which was reduced to $-2.27 \pm 0.97 \mathrm{D}$ and $-0.34 \pm 0.26 \mathrm{D}$ at 1 month after FTAK and 24 months after SMILE, respectively $(p<0.001)$. The surgically-induced astigmatism after FTAK, SMILE, and FTAK and SMILE combined was $3.38 \pm 1.18 \mathrm{D}, 2.22 \pm 0.84 \mathrm{D}$, and $5.39 \pm 1.20 \mathrm{D}$, respectively. Furthermore, the correction index of FTAK, SMILE, and FTAK and SMILE combined was $0.63 \pm 0.17,0.90 \pm 0.40$, and $0.98 \pm 0.06$, respectively. There were no intraoperative or postoperative complications.
\end{abstract}

Conclusion: Our surgical procedure combining FTAK and SMILE showed good and stable clinical outcomes during two-year follow-up for the treatment of high astigmatism.

Keywords: Astigmatism, Astigmatic keratotomy, Small incision lenticule extraction, SMILE, High astigmatism, Limbal relaxing incision, LRI

\section{Background}

Small-incision lenticule extraction (SMILE) is a flapless, all-femtosecond laser-based technique for correcting myopia and myopic astigmatism, which has gained widespread acceptance due to its good predictability, safety, and efficacy [1-3]. However, correction of high

* Correspondence: ytchungc@daum.net

${ }^{2}$ Onnuri Eye Hospital, 325, Baekje-daero, Wansan-gu, Jeonju-si, Jeollabuk-do, Republic of Korea

Full list of author information is available at the end of the article astigmatism with SMILE is still challenging. According to several studies, astigmatism remains $11 \sim 16 \%$ undercorrected after SMILE, with higher preoperative astigmatism increasing the amount of the astigmatic undercorrection [4-6]. And because astigmatic correction is also limited to 5.0 diopters (D), a large amount of astigmatic undercorrection is predicted to occur when treating an eye with more than $5.0 \mathrm{D}$ astigmatism using SMILE alone.

(c) The Author(s). 2021 Open Access This article is licensed under a Creative Commons Attribution 4.0 International License, which permits use, sharing, adaptation, distribution and reproduction in any medium or format, as long as you give appropriate credit to the original author(s) and the source, provide a link to the Creative Commons licence, and indicate if changes were made. The images or other third party material in this article are included in the article's Creative Commons licence, unless indicated otherwise in a credit line to the material. If material is not included in the article's Creative Commons licence and your intended use is not permitted by statutory regulation or exceeds the permitted use, you will need to obtain permission directly from the copyright holder. To view a copy of this licence, visit http://creativecommons.org/licenses/by/4.0/ The Creative Commons Public Domain Dedication waiver (http://creativecommons.org/publicdomain/zero/1.0/) applies to the data made available in this article, unless otherwise stated in a credit line to the data. 
Previously, we reported good short-term clinical outcomes after using a surgical procedure combining $\mathrm{cc}$ and SMILE for patients who were inoperable using SMILE alone due to high astigmatism [7]. However, the number of cases was small and the duration of follow-up was only 6 months. Furthermore, we only analyzed the magnitude of astigmatic correction by FTAK and SMILE did not perform vector analysis.

In the current study, we retrospectively analyzed the clinical outcomes after SMILE preceded by FTAK for eyes with over 4.0 D astigmatism. Furthermore, astigmatic changes were analyzed after each procedure individually and after the two of them using vector analysis.

\section{Methods}

\section{Patients}

This retrospective study recruited 75 eyes of 43 patients who were treated with SMILE after FTAK at the Onnuri Smile Eye Clinic, Seoul, Korea from October 2015 to February 2017. All eyes had preoperative astigmatism of $4.0 \mathrm{D}$ or more, a stable refraction for at least 1 year, and no preoperative topographic sign of keratoconus. Other inclusion criteria were a minimum age of 18 years, a corrected distance visual acuity (CDVA) of 20/25 or better, the absence of ocular disease, and a follow-up period of at least 2 years after SMILE. This study was approved by the Public Internal Regulatory Board of the Ministry of Health and Welfare, Korea (P01-202003-21-011). All procedures conformed to the tenets of the Declaration of Helsinki, and written informed consent for study participation was obtained from all patients.

Preoperatively, patients underwent a complete ophthalmologic examination including uncorrected distance visual acuity (UDVA), CDVA, manifest and cycloplegic refractions, slit-lamp microscopy, dilated fundus examination, specular microscopy (noncom Robo-ca; Konan Medical, Hyogo, Japan), and dual rotating Scheimpflug analyzer (Galilei ${ }^{\circ}$; Ziemer Ophthalmology, Port, Switzerland). Experienced optometrists performed all examinations.

\section{Full-thickness astigmatic keratotomy}

After scrubbing the skin and eyelids with povidoneiodine, the eyes were anesthetized with $0.5 \%$ proparacaine HCL (Alcaine ${ }^{\circ}$, Alcon, Fort Worth, TX, USA), and an eyelid speculum was used to keep the eye open in the recumbent position. The steepest axis was marked with a surgical marking pen with the aid of Callisto Eye system (Carl Zeiss AG, Dublin, CA), and a ring was marked with a $7.5-\mathrm{mm}$ diameter ring marker and gentian violet. A beveled full-thickness corneal incision was made using a $2.8-\mathrm{mm}$ keratome at $0,0.5,1.0$, or $1.5 \mathrm{~mm}$ from the posterior ring marking, and the incision tunnel was about $1.0 \mathrm{~mm}$ in length. The incision was widened using a wider keratome $(4.1$ or $5.7 \mathrm{~mm})$ depending on the magnitude of astigmatism (Table 1). One or two astigmatic keratotomies were performed according to the magnitude of preoperative astigmatism. The same nomogram as that used in our previous study was applied [7]. After checking for leakage with a Weck-Cel sponge, a mixture of cefazolin, prednisolone, and lidocaine in a 1:1:1 ratio was injected subconjunctivally near the incision. After the procedure, patients were treated with $0.5 \%$ moxifloxacin and $0.1 \%$ fluorometholone for 4 weeks.

\section{Small-incision Lenticule extraction}

SMILE was performed when the refraction had been stable for 2 weeks, at least 4 weeks after FTAK. Emmetropia was the target refraction for all eyes. The SMILE procedure was performed with $\mathrm{VisuMax}^{\circ}$ femtosecond laser (Carl Zeiss Meditec AG, Jena, Germany). The following laser parameters were used: $500-\mathrm{kHz}$ repetition rate, $140-n J$ pulse energy, $4.0-\mu \mathrm{m}$ spot spacing, 110 to $120-\mu \mathrm{m}$ cap thickness, and 6.0 to $6.7-\mathrm{mm}$ lenticule diameter according to the diameter of the scotopic pupil and manifest refraction. And an incision tunnel was located at the 11 o'clock position. The lenticule was separated with a blunt spatula using Chung's swing technique, as described in detail previously [8]. After removing the lenticule, the stromal pocket was flushed with balanced salt solution (BSS; Alcon). Following the procedure, patients were treated with $0.5 \%$ moxifloxacin for 5 days, $0.1 \%$ fluorometholone for 4 weeks, and preservative-free hyaluronic acid lubricating drops for at least 4 weeks.

\section{Outcome assessment}

Measurement of UDVA, CDVA, and manifest refraction was performed at 1 month after FTAK and 1, 6, 12, and 24 months after SMILE to assess visual and refractive outcomes. Slit-lamp examination and dual-rotating Scheimpflug analysis were performed at every follow-up to detect postoperative complications. To assess the changes in postoperative astigmatism, vector analyses were performed in this study using the Alpin's method $[8,9]$. In brief, refractive astigmatism at the spectacle plane was converted to the corneal plane using a vertex distance of $12 \mathrm{~mm}$. Refractive astigmatism was then analyzed by taking into account the change in the astigmatic axis and measuring 3 vectors and the relationships among them. The three vectors were defined as follows: the target induced astigmatism (TIA) vector represented the astigmatic change that the surgery intended to induce; the surgically induced astigmatism (SIA) vector represented the astigmatic change that the surgery actually induced; and the difference vector (DV) represented the difference between TIA and SIA. When the target 
Table 1 Nomogram of the full-thickness astigmatic keratotomy

\begin{tabular}{lll}
\hline Distance from corneal marking $(\mathbf{m m})$ & Incision width $(\mathbf{m m})$ & Corrected astigmatism (D) \\
\hline 1.5 & 2.8 & 0.75 \\
1.5 & 4.1 & 1.25 \\
1.5 & 5.7 & 2.5 \\
1.0 & 2.8 & 1 \\
1.0 & 4.1 & 1.75 \\
1.0 & 5.7 & 3 \\
0.5 & 4.1 & 2 \\
0.5 & 5.7 & 3.5 \\
0 & 5.7 & 4.5 \\
\hline
\end{tabular}

cylinder is emmetropia, DV is equal to the postoperative residual astigmatic vector. The magnitude of error (ME) is the arithmetic difference between the SIA and TIA in magnitude. The angle of error (AE) is half of the axis difference between SIA and TIA. Reported in degrees, $\mathrm{AE}$ values indicate a clockwise error of the axis when negative. The correction index (CI) was defined as the ratio of SIA to TIA. The value is ideally 1 ; values less than 1 represent an astigmatic undercorrection, while values larger than 1 represent an astigmatic overcorrection. The index of success (IS) was defined as DV divided by TIA. Preferably, the IS value should be 0 . Vector analyses were performed at three different time points, namely preoperatively, 1 month after FTAK, and 24 months after SMILE. The vector parameters of FTAK, SMILE, and FTAK and SMILE combined were subsequently compared. The safety index (the ratio between postoperative CDVA and preoperative CDVA) in addition to the efficacy index (the ratio between postoperative UDVA and preoperative CDVA) were calculated.

\section{Statistical analysis}

Graphs were made using Graphpad Prism (Prism version 8.1.0; Graphpad Inc., La Jolla, CA) and Microsoft Excel 2016 (Microsoft, Inc., Redmod, WA, USA). The data were analyzed with SPSS software (version 20.0; SPSS Inc., Chicago, IL). All values are given as means \pm standard deviation. All statistical analyses of visual acuity used logarithms of the minimum angle of resolution (logMAR). Statistical differences with $p<0.05$ were considered significant. One-way analysis of variance (ANOVA) was used to assess the time-course of changes in visual and refractive outcomes, as well as the vector parameters corresponding to the different surgical procedures. Correlation analyses were performed using Pearson's method.

\section{Results}

This study included 75 eyes from 43 patients. The refraction of all eyes was stable at 4 weeks after
FTAK, and all eyes had SMILE surgery at $4 \sim 6$ weeks after FTAK. The mean preoperative spherical equivalent (SE) was $-6.56 \pm 2.38 \mathrm{D}$ and the mean preoperative astigmatism was $-5.48 \pm 1.17$ D. Preoperative characteristics of the eyes are presented in Table 2 .

\section{Visual and refractive results}

The mean UDVA was $1.54 \pm 5.53 \log$ MAR preoperatively, compared to $1.58 \pm 0.47 \log \mathrm{MAR}$ at 1 month after FTAK $(p=0.079)$ and $-0.02 \pm 0.09 \log$ MAR at 24 months after SMILE $(p<0.001)$. The mean CDVA was $-0.03 \pm 0.07 \log$ MAR preoperatively, compared to $-0.04 \pm 0.05 \operatorname{logMAR}$ at 1 month after FTAK $(p=$ $0.138)$ and $-0.07 \pm 0.08 \log$ MAR at 24 months after SMILE $(p<0.001)$. Figure 1 shows changes in the UDVA and the CDVA following the surgical procedures, with the combined procedures having a significant effect on both the UDVA and the CDVA (both $p<0.001)$. While no significant change in SE was observable 1 month after FTAK $(p=0.357)$, the astigmatism reduced from $-5.48 \pm 1.17 \mathrm{D}$ to $-2.31 \pm 0.86 \mathrm{D}$, 1 month after FTAK $(p<0.001)$. Twenty-four months after SMILE, the mean SE was $-0.36 \pm 0.42 \mathrm{D}$ and the mean astigmatism was $-0.34 \pm 0.26 \mathrm{D}$. The effects

Table 2 Preoperative patient characteristics

\begin{tabular}{ll}
\hline Parameter & Mean \pm SD (range) \\
\hline Age (years) & $25.3 \pm 5.59$ (18 to 38$)$ \\
Sex (\% female) & 57.33 \\
LogMAR UDVA & $1.54 \pm 5.53(0.8$ to 2.0$)$ \\
LogMAR CDVA & $-0.03 \pm 0.07(-0.2$ to 0.2$)$ \\
CCT ( $\mu$ m) & $534.36 \pm 32.53(472$ to 611$)$ \\
Sphere (D) & $-3.82 \pm 2.56(-7.75$ to 2.25$)$ \\
Cylinder (D) & $-5.48 \pm 1.17(-9.0$ to -4.0$)$ \\
SE (D) & $-6.56 \pm 2.38(-10.875$ to -0.75$)$ \\
\hline
\end{tabular}

logMAR logarithm of the minimum angle of resolution, UDVA uncorrected distance visual acuity, CDVA corrected distance visual acuity, CCT central corneal thickness, $D$ diopters, $S E$ spherical equivalent 

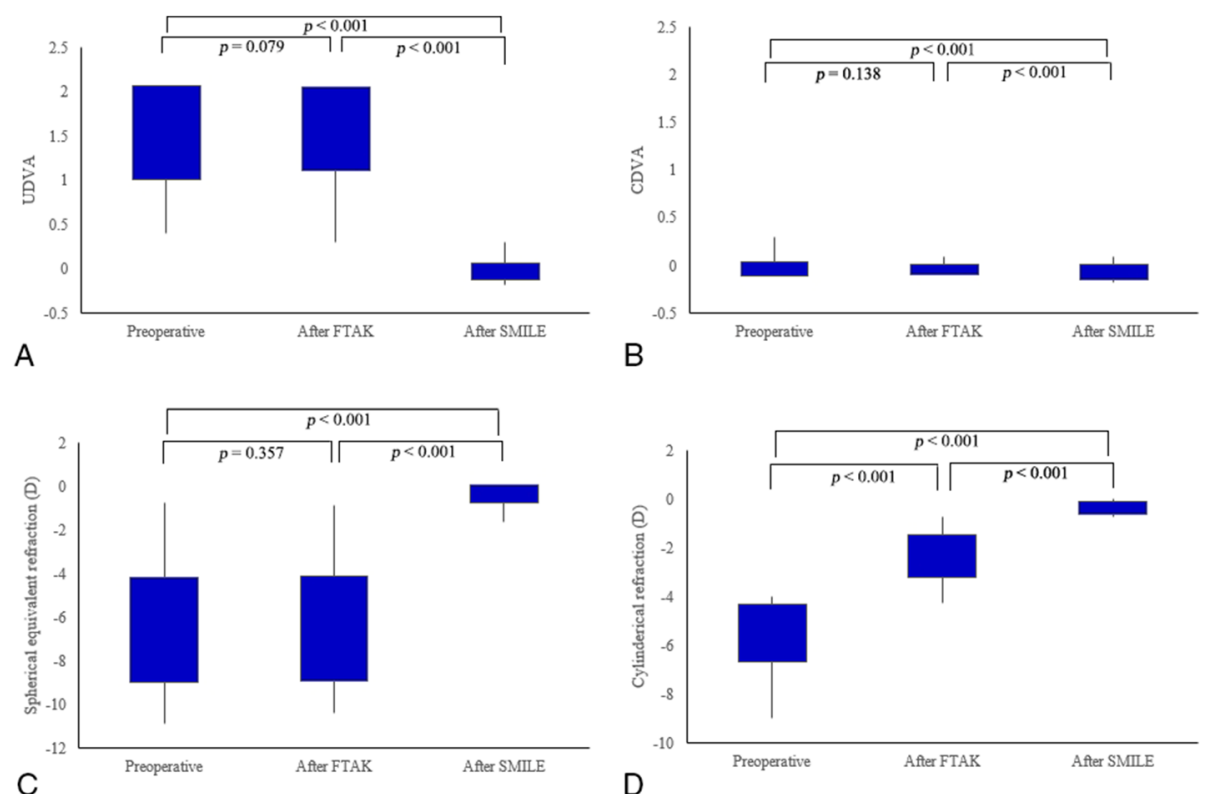

Fig. 1 Visual acuities and refractive outcomes at 1 month after full-thickness astigmatic keratotomy (FTAK) and 24 months after small-incision lenticule extraction (SMILE). a Changes in uncorrected distance visual acuity. b Changes in corrected distance visual acuity. c Changes in spherical equivalent refraction. $\mathbf{d}$ Changes in cylindrical refraction

of the combined procedures on both SE and astigmatism were significant (both $p<0.001$ ).

A UDVA of $20 / 20$ or better was achieved by $79 \%$ of the eyes at 24 months postoperatively (Fig. 2a). The UDVA was $0.001 \pm 0.07 \operatorname{logMAR}$ at 1 month after SMILE and did not change during the postoperative period ( $p=0.082$, Table 3). Also at the 24-month followup, 75 and $95 \%$ of the eyes were within $\pm 0.5 \mathrm{D}$ and \pm 1.0 $\mathrm{D}$ of attempted SE, respectively (Fig. 2e). Correlation between attempted versus achieved SE refraction was high $\left(R^{2}=0.9733\right.$, Fig. $\left.2 d\right)$. Moreover, $51 \%$ of the eyes had an unchanged CDVA, $4 \%$ lost one Snellen line or more, and $45 \%$ gained one Snellen line or more (Fig. 2c). The mean CDVA was $-0.05 \pm 0.08 \log$ MAR at 1 month after SMILE and did not change during the postoperative period $(p=0.272$, Table 3). Overall, the mean SE was stable and did not show significant change throughout the postoperative period $(p=0.441$, Table 3$)$, with $0.36 \pm 0.42 \mathrm{D}$ at 24 months (Fig. 1f). The efficacy and safety indices at 24 months after SMILE were $1.01 \pm 0.24$ and $1.10 \pm 0.17$, respectively. After the combined procedures, there was no change in the efficacy and safety indices during the follow-up period (Table 3).

\section{Outcomes of astigmatism correction and vector analysis}

Table 4 shows the vector analysis results for each procedure when used individually or combined. Singleangle polar plots with a mean TIA, SIA, and DV vector for FTAK, SMILE, and the two procedures combined are shown in Fig. 3. Because the target refraction was emmetropia, the TIA represented astigmatism before the procedure and the DV represented the residual astigmatism after each procedure. The mean DV results were $2.27 \mathrm{D} \times 175^{\circ}$ after FTAK and $0.34 \mathrm{D} \times 178^{\circ}$ after both SMILE and the two procedures combined, indicating 2.27 D undercorrection after FTAK and 0.34 D undercorrection after both SMILE and the two procedures combined.

The SIA results were $3.38 \pm 1.18,2.22 \pm 0.84$, and $5.39 \pm 1.20$ after FTAK, SMILE, and the two procedures combined, respectively; this difference was statistically significant $(p<0.001)$. The mean $\mathrm{AE}$ values were $2.08 \pm$ $5.47,-0.67 \pm 4.67$, and $-0.12 \pm 1.14$ after FTAK, SMILE, and the two procedures combined, respectively; all values were significantly different from zero $(p<0.001)$, indicating that the achieved correction was located in the clockwise direction to the intended axis for SMILE and in the two procedures combined, and in the counterclockwise direction to the intended axis for FTAK. The mean ME was $-2.10 \pm 1.02,-0.04 \pm 0.55$, and $0.09 \pm 0.36$ after FTAK, SMILE, and the two procedures combined; all values were negative, indicating undercorrection. The CI results were all under 1 , indicating undercorrection of astigmatism after each procedure and their combination. However, the $\mathrm{CI}$ for the two procedures combined was $0.98 \pm 0.06$, which was significantly high compared to the CI of both FTAK and SMILE individually $(p<0.001)$. The regression line between TIA and SIA had a slope of 0.627, 0.897, and 0.975 , indicating $37.3,10.3$, and $2.5 \%$ of astigmatism 


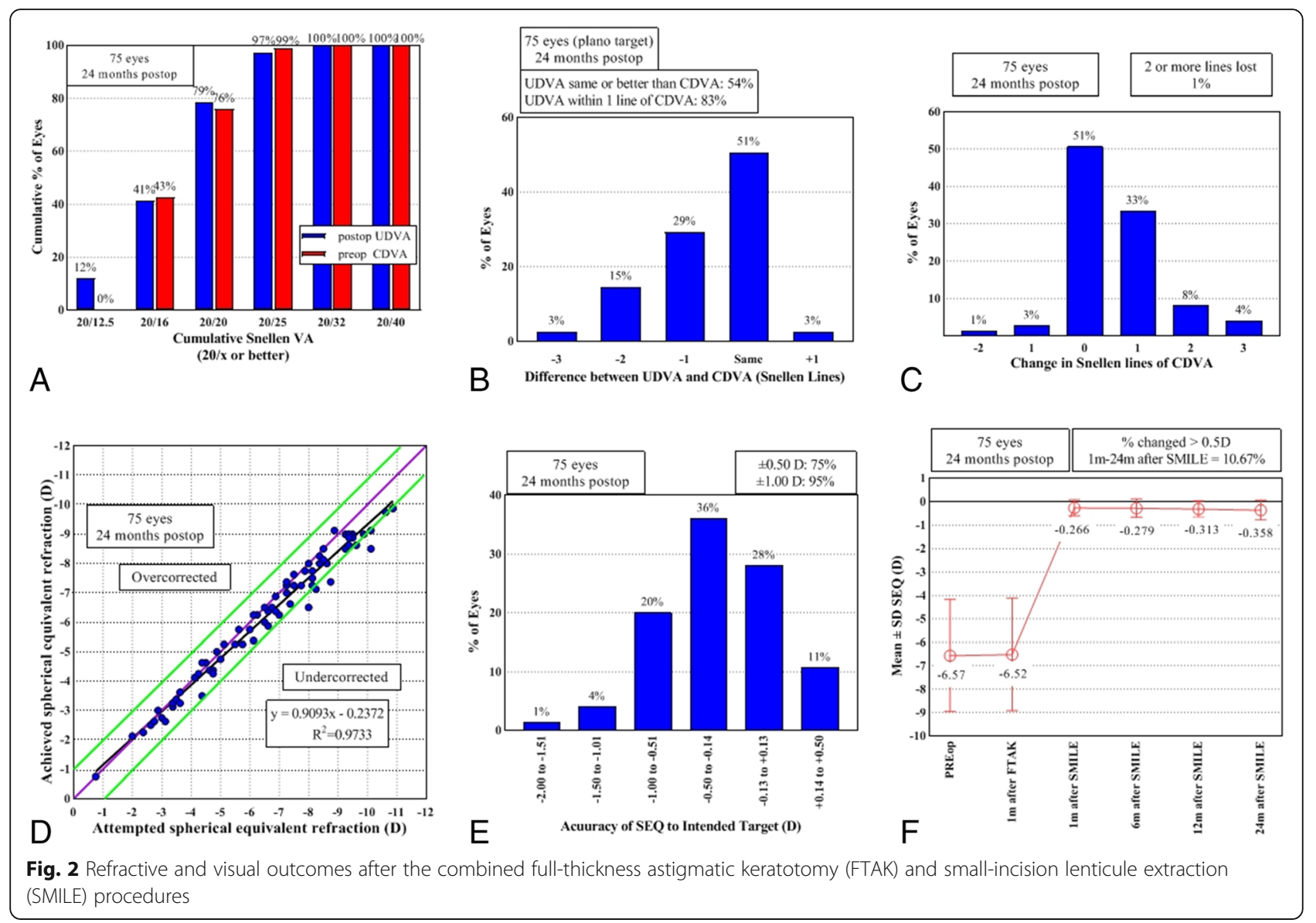

undercorrection after FTAK, SMILE, and the two procedures combined, respectively (Fig. 4).

A tendency towards increased undercorrection with a high level of TIA can be seen in Fig. 5. This observation was statistically significant after individual FTAK and SMILE procedures (both $p<0.001$ ), but was not statistically significant after the two procedures combined ( $p=$ $0.489)$.

\section{Safety and complications}

There were no intraoperative or postoperative complications such as of wound dehiscence, infection, epithelial ingrowth, or ectasia during the follow-up period. Also, there was no significant change in the endothelial cell number $(p=0.272)$.

\section{Discussion}

The reasons for the failure to fully correct astigmatism when using SMILE are not fully understood. There have been several possible causes of astigmatic undercorrection after SMILE suggested by many authors. Because of the lack of an active eye tracker, the centration of treatment in SMILE is purely subjective and may vary greatly between surgeons. In addition, there is no standardized method to determine the center of the optic zone, which can be the pupil center or the corneal vertex. Yu et al. [10] found that the decentration was $0.27 \pm 0.09 \mathrm{~mm}$ from the corneal vertex, and Lazaridis et al. [11] reported a mean decentration of $0.31 \pm 0.21 \mathrm{~mm}$ after SMILE. However, laser in situ keratomileusis (LASIK) procedures that harbor an active eye tracker also cause decentration of ablation. Some authors reported no significant difference in decentration between LASIK and SMILE [11, 12], and Chan et al. [12] found no significant association between decentration and astigmatic correction after LASIK and SMILE. Cyclotorsion of the eye from standing to supine position is another possible cause of astigmatic undercorrecion after refractive surgery [13]. Moreover, because Visumax does not harbor a cyclotorsion compensation system, cyclotorsion is one of the biggest concerns when treating eyes with high astigmatism through SMILE. Some authors reported axis misalignment after SMILE and the superiority of LASIK in correcting low-to-moderate astigmatism, which was explained by the lack of a cyclotorsion compensation system in SMILE $[4,14,15]$. To compensate for cyclotorsion, manual compensation using corneal marking in the sitting position and rotation of the con after docking 
Table 3 Visual acuities, refractive errors, efficacy index, and safety index

\begin{tabular}{|c|c|c|c|c|c|c|c|}
\hline & Preoperative & $\begin{array}{l}1 \text { month after } \\
\text { FTAK }\end{array}$ & $\begin{array}{l}1 \text { month after } \\
\text { SMILE }\end{array}$ & $\begin{array}{l}6 \text { months after } \\
\text { SMILE }\end{array}$ & $\begin{array}{l}12 \text { months after } \\
\text { SMILE }\end{array}$ & $\begin{array}{l}24 \text { months after } \\
\text { SMILE }\end{array}$ & $p$ value \\
\hline $\begin{array}{l}\text { LOgMAR } \\
\text { UDVA }\end{array}$ & $\begin{array}{l}1.54 \pm 5.53 \\
(0.8 \text { to } 2.0)\end{array}$ & $\begin{array}{l}1.58 \pm 0.47 \\
(0.5 \text { to } 2.00)\end{array}$ & $\begin{array}{l}0.001 \pm 0.07 \\
(-0.1 \text { to } 0.1)\end{array}$ & $\begin{array}{l}-0.03 \pm 0.06(-0.2 \text { to } \\
0.1)\end{array}$ & $\begin{array}{l}-0.03 \pm 0.07(-0.2 \\
\text { to } 0.1)\end{array}$ & $\begin{array}{l}-0.02 \pm 0.09(-0.2 \\
\text { to } 0.1)\end{array}$ & 0.082 \\
\hline $\begin{array}{l}\text { LogMAR } \\
\text { CDVA }\end{array}$ & $\begin{array}{l}-0.03 \pm 0.07 \\
(-0.2 \text { to } 0.2)\end{array}$ & $\begin{array}{l}-0.04 \pm 0.05 \\
(-0.2 \text { to } 0.2)\end{array}$ & $\begin{array}{l}-0.05 \pm 0.08 \\
(-0.2 \text { to } 0.1)\end{array}$ & $\begin{array}{l}-0.07 \pm 0.07(-0.2 \text { to } \\
0.1)\end{array}$ & $\begin{array}{l}-0.06 \pm 0.07(-0.2 \\
\text { to } 0.1)\end{array}$ & $\begin{array}{l}-0.07 \pm 0.08(-0.2 \\
\text { to } 0.1)\end{array}$ & 0.272 \\
\hline Sphere (D) & $\begin{array}{l}-3.82 \pm 2.56 \\
(-7.75 \text { to }+2.25)\end{array}$ & $\begin{array}{l}-5.37 \pm 2.60 \\
(-9.25 \text { to }-0.25)\end{array}$ & $\begin{array}{l}-0.08 \pm 0.30 \\
(-0.75 \text { to } 0.75)\end{array}$ & $\begin{array}{l}-0.12 \pm 0.37(-1.5 \text { to } \\
0.75)\end{array}$ & $\begin{array}{l}-0.14 \pm 0.35(-1.0 \\
\text { to } 0.5)\end{array}$ & $\begin{array}{l}-0.19 \pm 0.41(-1.5 \\
\text { to } 0.5)\end{array}$ & 0.382 \\
\hline $\begin{array}{l}\text { Cylinder } \\
\text { (D) }\end{array}$ & $\begin{array}{l}-5.48 \pm 1.17 \\
(-9.0 \text { to }-4.0)\end{array}$ & $\begin{array}{l}-2.27 \pm 0.97 \\
(-4.25 \text { to }-0.25)\end{array}$ & $\begin{array}{l}-0.36 \pm 0.28 \\
(-1.0 \text { to } 0)\end{array}$ & $\begin{array}{l}-0.33 \pm 0.26(-1.0 \text { to } \\
0)\end{array}$ & $\begin{array}{l}-0.34 \pm 0.29(-1.25 \\
\text { to } 0)\end{array}$ & $\begin{array}{l}-0.34 \pm 0.26(-1.0 \\
\text { to } 0)\end{array}$ & 0.946 \\
\hline SE (D) & $\begin{array}{l}-6.56 \pm 2.38 \\
(-10.875 \text { to }-0.75)\end{array}$ & $\begin{array}{l}-6.52 \pm 2.40 \\
(-10.375 \text { to }-0.875)\end{array}$ & $\begin{array}{l}-0.27 \pm 0.33 \\
(-0.875 \text { to } 0.375)\end{array}$ & $\begin{array}{l}-0.29 \pm 0.38(-1.625 \\
\text { to } 0.625)\end{array}$ & $\begin{array}{l}-0.31 \pm 0.34(- \\
1.125 \text { to } 0.25)\end{array}$ & $\begin{array}{l}-0.36 \pm 0.42(- \\
1.625 \text { to } 0.25)\end{array}$ & 0.441 \\
\hline $\begin{array}{l}\text { Efficacy } \\
\text { index }\end{array}$ & - & $\begin{array}{l}0.05 \pm 0.08 \\
(0.01 \text { to } 0.5)\end{array}$ & $\begin{array}{l}0.94 \pm 0.16 \\
\text { (0.58 to } 1.43)\end{array}$ & $\begin{array}{l}1.00 \pm 0.19 \text { (0.67 to } \\
1.71)\end{array}$ & $\begin{array}{l}1.01 \pm 0.17 \text { (0.67 to } \\
1.5)\end{array}$ & $\begin{array}{l}1.01 \pm 0.24 \text { (0.56 to } \\
1.71)\end{array}$ & 0.130 \\
\hline $\begin{array}{l}\text { Safety } \\
\text { index }\end{array}$ & - & $\begin{array}{l}1.02 \pm 0.10 \\
(0.83 \text { to } 1.6)\end{array}$ & $\begin{array}{l}1.06 \pm 0.21 \\
(0.58 \text { to } 1.71)\end{array}$ & $\begin{array}{l}1.10 \pm 0.17 \text { (0.83 to } \\
1.71)\end{array}$ & $\begin{array}{l}1.09 \pm 0.16 \text { (0.83 to } \\
1.43)\end{array}$ & $\begin{array}{l}1.10 \pm 0.17 \text { (0.83 to } \\
1.71)\end{array}$ & 0.292 \\
\hline
\end{tabular}

FTAK full-thickness astigmatic keratotomy, SMILE small-incision lenticule extraction, logMAR logarithm of the minimum angle of resolution, UDVA uncorrected distance visual acuity, CDVA corrected distance visual acuity, $D$ diopters, SE spherical equivalent. Values are presented as mean \pm standard deviation (range) $p$ value of postoperative measurement (after SMILE), with one-way ANOVA

was suggested during SMILE, with some reports of better astigmatic correction [16, 17]. However, according to an observation reported by Ganesh et al. [16], 86\% of eyes with a high cylinder demonstrated 5 degrees or less of cyclotorsion with none having 10 or more degrees, and the manual marking method could inherently introduce inconsistency ranging from 3.8 to 6.0 degrees. Moreover, a recent study yielded comparable results between SMILE and LASIK when treating over 3.0 D of astigmatism without the use of the manual corneal marking method during SMILE [18]. Besides, there are other factors that may influence astigmatic correction by SMILE, including ocular residual astigmatism, angle kappa, anterior corneal curvature, preoperative axis of astigmatism, and the technique of lenticule extraction [12, 19-22]. Several adjustments of current treatment nomograms have been suggested, leading to a $10 \%$ increment in the magnitude of astigmatism correction $[4,23]$.

Table 4 Vector parameters for full-thickness astigmatic keratotomy (FTAK), small-incision lenticule extraction (SMILE), and the two procedures combined

\begin{tabular}{lllll}
\hline & FTAK & SMILE & FTAK + SMILE & $\boldsymbol{p}$ value \\
\hline TIA & $5.48 \pm 1.17$ & $2.27 \pm 0.97$ & $5.48 \pm 1.17$ & $<0.001$ \\
SIA & $3.38 \pm 1.18$ & $2.22 \pm 0.84$ & $5.39 \pm 1.20$ & $<0.001$ \\
DV & $2.27 \pm 0.97$ & $0.34 \pm 0.26$ & $0.34 \pm 0.26$ & $<0.001$ \\
ME & $-2.10 \pm 1.02$ & $-0.04 \pm 0.55$ & $-0.09 \pm 0.36$ & $<0.001$ \\
AE & $2.08 \pm 5.47$ & $-0.67 \pm 4.67$ & $-0.12 \pm 1.14$ & $<0.001$ \\
Cl & $0.63 \pm 0.17$ & $0.90 \pm 0.40$ & $0.98 \pm 0.06$ & $<0.001$ \\
IS & $0.41 \pm 0.17$ & $0.05 \pm 0.33$ & $0.06 \pm 0.05$ & $<0.001$
\end{tabular}

$T I A$ target-induced astigmatism, SIA surgically-induced astigmatism, $D V$ difference vector, $M E$ magnitude of error, $A E$ angle of error, $C l$ correction index, IS index of success

$p$ value with one-way ANOVA
Currently, however, there are no standardized nomograms for astigmatism correction.

Although many causes have been suggested for astigmatic undercorrection after SMILE and methods have been proposed to remediate them, none of them has been proved to be true or effective. However, there is a clear tendency that the greater the preoperative astigmatism, the higher the degree of undercorrection [4-6]. Ivarsen and Hjordtal [6] thus reported that an undercorrection of $13 \%$ per diopter of attempted correction was observed after treatment of low astigmatism, compared to $16 \%$ after treatment of high astigmatism after SMILE. Furthermore, Pederson et al. [4] found that 94 and $63 \%$ of patients with 0.5 to $1.0 \mathrm{D}$ and 3.0 to $4.0 \mathrm{D}$ preoperative astigmatism had an ME of less than $0.5 \mathrm{D}$, respectively.

In the current study, we focused on refraction. Preoperative high astigmatism is one of the biggest risk factors for astigmatic undercorrection, and high astigmatic cornea can cause decentration during suction because of the discrepancy between the corneal curvature and the contact glass surface during SMILE [12]. We thus performed FTAK prior to SMILE to reduce the amount of astigmatism, and hence expect better predictability of SMILE. The steep cornea was flattened by FTAK, which was expected to be helpful in centrating during suction. Furthermore, we also aimed to reduce the lenticule thickness by performing FTAK, thereby reducing astigmatism without altering the spherical equivalent [24]. Moreover, because currently, SMILE is limited to a refractive correction of up to $5.0 \mathrm{D}$ for astigmatism, we could make SMILE applicable to patients who had more than $5.0 \mathrm{D}$ astigmatism preoperatively. We previously reported good 


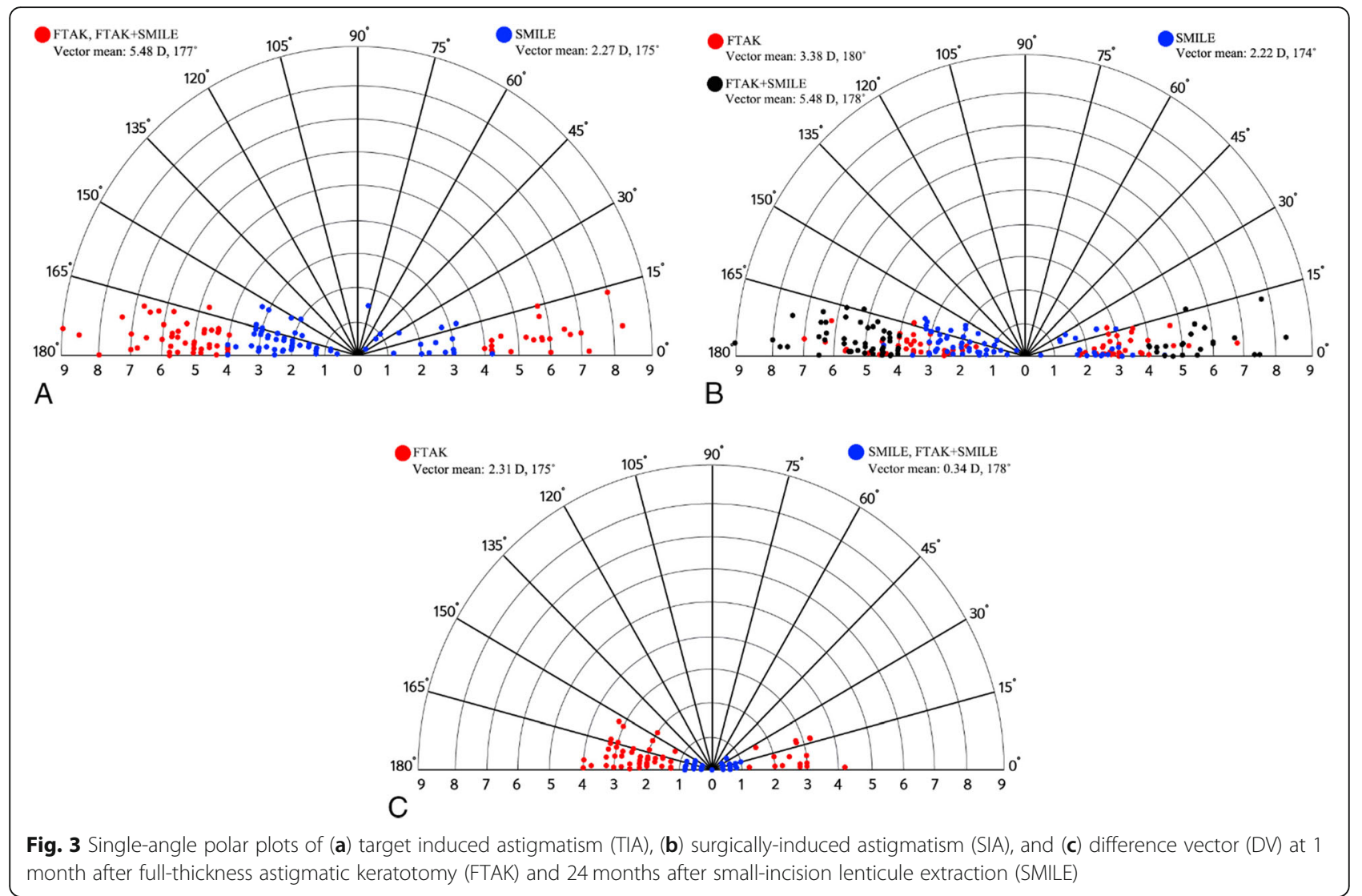

efficacy and predictability for the combination of FTAK and SMILE in patients with high astigmatism [7]. However, the follow-up period was of only 6 months, the number of eyes that were included were 13 , and no vector analysis was conducted. Herein, we evaluated the effectiveness of astigmatic correction by FTAK and SMILE, both individually and combined, in patients with over $4.0 \mathrm{D}$ astigmatism preoperatively using Alpin's vector method during a 2-year followup period.

The current study demonstrated that when combined, FTAK and SMILE procedures yielded good efficacy, safety, and predictability in correcting eyes with high astigmatism. In our study, an average undercorrection of DV of $0.34 \mathrm{D} \times 178^{\circ}$ was found 24 months after the combined FTAK and SMILE procedures. Pederson et al. [4]
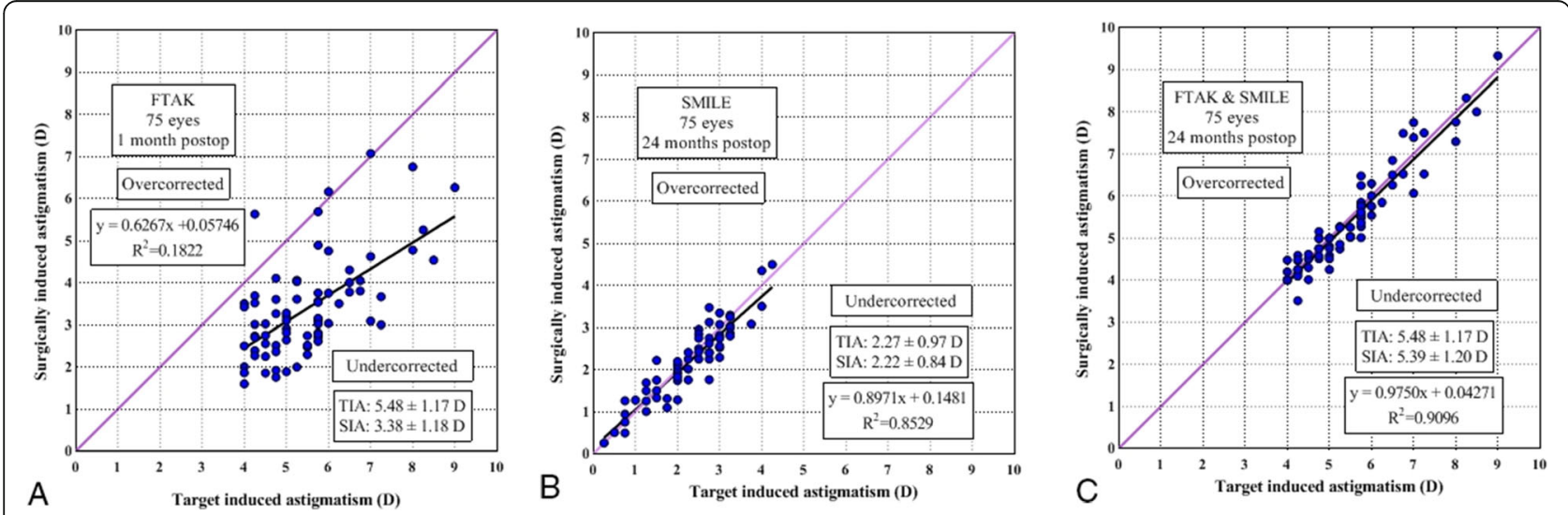

Fig. 4 Scatterplot of the target induced astigmatism (TIA) versus surgically-induced astigmatism (SIA) of (a) full-thickness astigmatic keratotomy (FTAK), (b) small-incision lenticule extraction (SMILE), and (c) the two procedures combined 

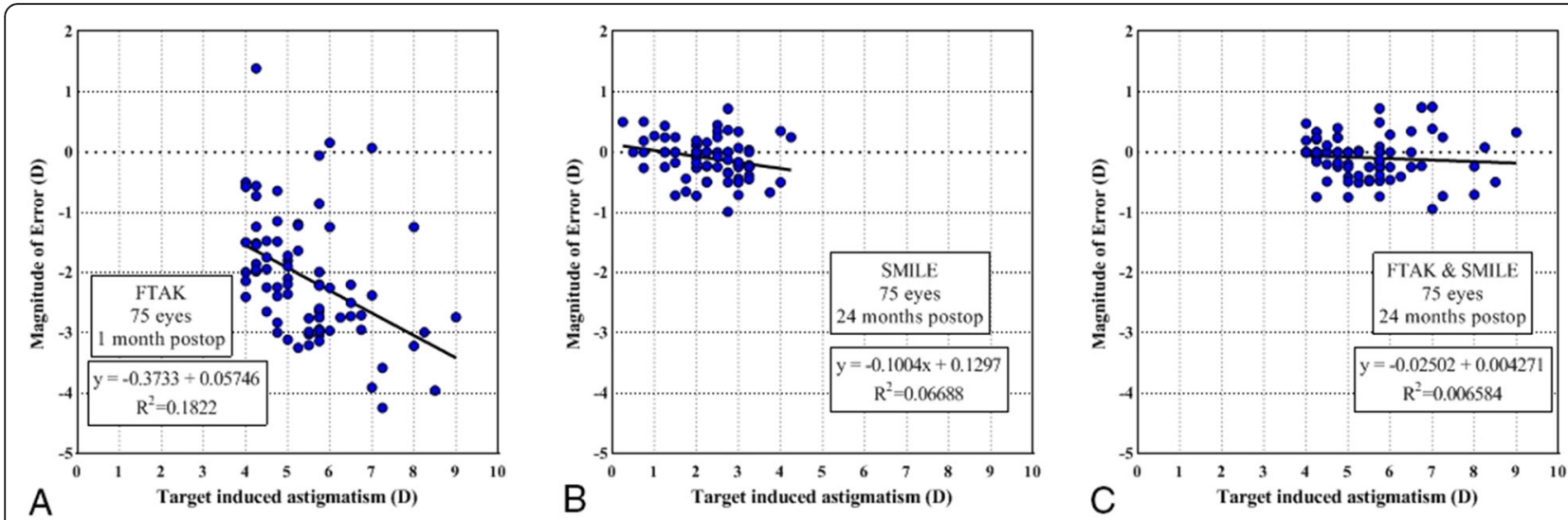

Fig. 5 Magnitude of error (ME) versus target induced astigmatism (TIA) after (a) full-thickness astigmatic keratotomy (FTAK), (b) small-incision lenticule extraction (SMILE), and (c) the two procedures combined

reported an average undercorrection of DV of $0.31 \mathrm{D} \times$ $91^{\circ}$ for eyes with a mean astigmatism of $1.81 \pm 1.0$ (range: 0.75 to $4.0 \mathrm{D}$ ) at 1 year after SMILE. Considering that the preoperative mean astigmatism in our study was $5.48 \pm 1.17 \mathrm{D}$ (range: 4.0 to $9.0 \mathrm{D}$ ) and $54.7 \%$ of eyes had over $5.0 \mathrm{D}$ of astigmatism preoperatively, and were thus inoperable by SMILE alone, the combined FTAK and SMILE procedures showed good effectiveness of astigmatic correction. According to prior studies, the amount of undercorrection after SMILE tends to increase with higher preoperative astigmatism [4-6]. In our study, a tendency toward increased undercorrection with a high level of preoperative astigmatism was not statistically significant after FTAK and SMILE combined $(p=0.489)$, whereas it was statistically significant after FTAK and SMILE individually (both $p<0.001$ ). We suggest that this was because the astigmatism was reduced after FTAK, so the TIA of SMILE was relatively low and the predictability of SMILE was increased. Furthermore, 79\% of eyes achieved a UDVA of $20 / 20$ or better, $96 \%$ of eyes had a CDVA that was equal to or better than preoperative CDVA, and the postoperative SE was $-0.36 \pm 0.42$ $\mathrm{D}$ at 24 months after the combined procedures. No complication was observed during the 2-year follow-up period.

Astigmatic keratotomy (AK) is an effective procedure for the correction of naturally-occurring astigmatism as well as any residual astigmatism in patients who underwent LASIK, lensectomy, or keratoplasty [25-27]. However, the predictability of AK is poor, especially when correcting higher astigmatism [26]. Recently, many authors reported better results using femtosecond laser technology with AK [28-30]. Loriaut et al. [28] reported a mean CI of 0.9 of femtosecond-assisted AK in post-keratoplasty astigmatism, but $50 \%$ of eyes were overcorrected. Although the CI of FTAK was 0.63 in our study, only 3 eyes
(4\%) were overcorrected with FTAK, including 2 eyes that were overcorrected by less than $0.5 \mathrm{D}$ (Fig. 4). That was because we did not have $1 \mathrm{CI}$ as our target for FTAK. Rather, we performed a FTAK procedure to reduce astigmatism so that the accuracy of astigmatic correction with SMILE could be improved. In our study, the mean safety index was $1.02 \pm 0.10$ after FTAK, which was lower than the safety indices of 1.59, 1.29 reported by Loriaut et al. [28] and Fadlallah et al. [29], respectively. We suggest that this is because these two previous studies performed AK on post-keratoplasty eyes whereas virgin eyes were used in our study, and preoperative CDVAs were $0.5 \pm 0.3$ and $0.51 \pm 0.26 \log$ MAR in Loriaut et al. [28] and Fadlallah et al. [29]'s studies, respectively, which was lower compared to $-0.03 \pm 0.07 \log$ MAR in our preoperative CDVA. Even though we used manual incision, full-thickness incision with a uniform keratome was used to avoid inaccuracies in incision depth and length, and we achieved satisfactory results in astigmatism reduction with FTAK, with a SIA of $3.38 \pm$ $1.18 \mathrm{D}$ at 1 month postoperatively. Importantly, we did not note any complications such as wound leak, endophthalmitis, or retinal detachment after FTAK during the follow-up period. It is thought that the long tunnel incision helped prevent not only regression of astigmatism but also wound leakage.

There may be some concerns about refraction change after FTAK as a result from corneal healing [25, 29]. Some authors reported postoperative increase in astigmatism after partial thickness AK on post-keratoplasty eyes, but we performed full-thickness incision, which is preventive of astigmatic regression, on eyes with naturally-occurring astigmatism. Furthermore, there was no significant change in postoperative astigmatism 1 month after FTAK in our previous studies about FTAK $[7,31]$. All eyes, in our study, had a stable refraction at 
4 weeks after FTAK, so all SMILE procedures were performed within $4 \sim 6$ weeks after FTAK. Finally, inaccuracy in astigmatic correction of astigmatic keratotomy may also be a big concern. However, in our study, because residual astigmatism was subsequently corrected with SMILE, any potential inaccuracy did not pose any problems.

In this study, at 1 month after FTAK, SE was not changed compared to preoperative SE $(p=0.357)$. And the mean DV of FTAK was $2.27 \pm 0.97 \mathrm{D}$, which may also be considered as the TIA for SMILE. The amount of astigmatic correction by SMILE was comparable with the results of other studies [4-6]. In the current study, an undercorrection of $10.3 \%$ was observed after SMILE, and there was a tendency towards increased undercorrection with a high level of TIA. We suggest that this is because the astigmatism range was 0.25 to 4.25 after FTAK, which was comparable to previous studies, and FTAK was done on the peripheral corneal zone, thereby saving the optic zone.

Two limitations of this study were the lack of evaluation of the causes underlying astigmatic undercorrection and its retrospective design. A prospective study examining the relationship between decentration and the amount of astigmatic undercorrection or a comparative study evaluating the efficacy of SMILE alone versus SMILE combined with FTAK in eyes with $4.0 \sim 5.0 \mathrm{D}$ are thus warranted to corroborate our findings.

\section{Conclusions}

The current study found that combination FTAK and SMILE showed good and stable clinical outcomes during two-year follow-up for the treatment of high astigmatism.

\begin{abstract}
Abbreviations
SMILE: Small-incision lenticule extraction; FTAK: Full-thickness astigmatic keratotomy; CDVA: Corrected distance visual acuity; UDVA: Uncorrected distance visual acuity; logMAR: Logarithms of the minimum angle of resolution; TIA: Target induced astigmatism; SIA: Surgically induced astigmatism; DV: Difference vector; ME: Magnitude of error; AE: Angle of error; Cl: Correction index; IS: Index of success
\end{abstract}

\section{Acknowledgements}

Not applicable.

\section{Authors' contributions}

Literature screening and selection was performed by BKK. BKK and YTC participated in the design of the study. BKK drafted the manuscript, and carried out the statistical analysis. YTC interpreted the data. BKK and YTC prepare and review of the manuscript. YTC have given final approval of the version to be published. All authors read and approved the final manuscript.

\section{Funding}

There was no funding sources for this study.

\section{Availability of data and materials}

All data generated or analyzed during this study are available from the corresponding author on reasonable request.

\section{Ethics approval and consent to participate}

The study was protocol was reviewed and approved by the Public Internal Regulatory Board of the Ministry of Health and Welfare, Korea. It also strictly adhered to the principles of the Declaration of Helsinki, and written informed consent for study participation was obtained from all patients.

\section{Consent for publication}

Not applicable.

\section{Competing interests}

All authors declare that they have no competing interests.

\section{Author details}

${ }^{1}$ Onnuri Smile Eye Clinic, Hyobong building 9F 1, Gangnam-daero 65 gil, Seocho-gu, Seoul, Republic of Korea. ${ }^{2}$ Onnuri Eye Hospital, 325, Baekje-daero, Wansan-gu, Jeonju-si, Jeollabuk-do, Republic of Korea.

Received: 15 July 2020 Accepted: 4 December 2020

Published online: 09 January 2021

\section{References}

1. Shah R, Shah S, Sengupta S. Results of small incision lenticule extraction: allin-one femtosecond laser refractive surgery. J Cataract Refract Surg. 2011;37: 127-37.

2. Sekundo W, Kunert KS, Blum M. Small incision corneal refractive surgery using the small incision lenticule extraction (SMILE) procedure for the correction of myopia and myopic astigmatism: results of a 6-month prospective study. Br J Ophthalmol. 2011;95:335-9.

3. Kim JR, Kim BK, Mun SJ, et al. One-year outcomes of small-incision lenticule extraction (SMILE): mild to moderate myopia vs. high myopia. BMC Ophthalmol. 2015;15:59.

4. Pedersen IB, Ivarsen A, Hjortdal J. Changes in astigmatism, densitometry, and aberrations after SMILE for low to high myopic astigmatism: a 12month prospective study. J Refract Surg. 2017;33:11-7.

5. Zhang J, Wang Y, Wu W, et al. Vector analysis of low to moderate astigmatism with small incision lenticule extraction (SMILE): results of a 1year follow-up. BMC Ophthalmol. 2015;15:8.

6. Ivarsen A, Hjortdal J. Correction of myopic astigmatism with small incision lenticule extraction. J Refract Surg. 2014;30:240-7.

7. Kim BK, Mun SJ, Lee DG, et al. Full-thickness astigmatic keratotomy combined with small-incision lenticule extraction to treat high-level and mixed astigmatism. Cornea. 2015;34:1582-7.

8. Alpins NA. A new method of analyzing vectors to treat astigmatism. J Cataract Refract Surg. 1993;19:524-33.

9. Alpins NA. New method of targeting vectors to treat astigmatism. J Cataract Refract Surg. 1997;23:65-75.

10. Yu Y, Zhang W, Cheng X, Cai J, Chen H. Impact of Treatment Decentration on Higher-Order Aberrations after SMILE. J Ophthalmol. 2017;2017:9575723. https://doi.org/10.1155/2017/9575723.

11. Lazaridis A, Droutsas K, Sekundo W. Topographic analysis of the centration of the treatment zone after SMILE for myopia and comparison to FS-LASIK: subjective versus objective alignment. J Refract Surg. 2014;30:680-6.

12. Chan TCY, Wan KH, Kang DSY, et al. Effect of corneal curvature on optical zone decentration and its impact on astigmatism and higher-order aberrations in SMILE and LASIK. Graefes Arch Clin Exp Ophthalmol. 2019; 257:233-40.

13. Chernyak DA. Cyclotorsional eye motion occurring between wavefront measurement and refractive surgery. J Cataract Refract Surg. 2004;30:633-8.

14. Chan TC, Ng AL, Cheng GP, et al. Vector analysis of astigmatic correction after small-incision lenticule extraction and femtosecond-assisted LASIK for low to moderate myopic astigmatism. Br J Ophthalmol. 2016;100:553-9.

15. Khalifa MA, Ghoneim AM, Shaheen MS, et al. Vector analysis of astigmatic changes after small-incision lenticule extraction and wavefrontguided laser in situ keratomileusis. J Cataract Refract Surg. 2017;43:819-24.

16. Ganesh S, Brar S, Pawar A. Results of intraoperative manual cyclotorsion compensation for myopic astigmatism in patients undergoing small incision lenticule extraction (SMILE). J Refract Surg. 2017;33:506-12.

17. Jun I, Kang DSY, Reinstein DZ, et al. Clinical outcomes of SMILE with a triple centration technique and corneal wavefront-guided transepithelial PRK in high astigmatism. J Refract Surg. 2018;34:156-63. 
18. Chan TCY, Wang Y, Ng ALK, et al. Vector analysis of high ( $>/ 1 / 43$ diopters) astigmatism correction using small-incision lenticule extraction and laser in situ keratomileusis. J Cataract Refract Surg. 2018;44:802-10.

19. Moshirfar M, Hoggan RN, Muthappan V. Angle kappa and its importance in refractive surgery. Oman J Ophthalmol. 2013;6:151-8.

20. Qian Y, Huang J, Chu R. Influence of intraocular astigmatism on the correction of myopic astigmatism by femtosecond laser small-incision lenticule extraction. J Cataract Refract Surg. 2015;41:1057-64.

21. Ivarsen A, Gyldenkerne A, Hjortdal J. Correction of astigmatism with smallincision lenticule extraction: impact of against-the-rule and with-the rule astigmatism. J Cataract Refract Surg. 2018:44:1066-72.

22. Chan TCY, Ng ALK, Cheng GPM. Effect of the learning curve on visual and refractive outcomes of small-incision lenticule extraction. Cornea. 2017;36: 1044-50.

23. Alio Del Barrio JL, Vargas V, Al-Shymali O, et al. Small incision lenticule extraction (SMILE) in the correction of myopic astigmatism: outcomes and limitations_an update. Eye Vis. 2017:4:26

24. Lindquist TD, Rubenstein JB, Rice SW, et al. Trapezoidal astigmatickeratotomy. Quantification in human cadaver eyes. Arch Ophthalmol. 1986;104:1534-9.

25. Cleary $\mathrm{C}$, Tang $\mathrm{M}$, Ahmed $\mathrm{H}$, et al. Beveled femtosecond laser astigmatic keratotomy for the treatment of high astigmatism post-penetrating keratoplasty. Cornea. 2013;32:54-62.

26. Guell JL, Manero F, Müller A. Transverse keratotomy to correct high corneal astigmatism after cataract surgery. J Cataract Refract Surg. 1996;22:331-6.

27. Pineda R, Jain V. Arcuate keratotomy: an option for astigmatism correction after laser in situ keratomileusis. Cornea. 2009;28:1178-80.

28. Loriaut P, Borderie VM, Laroche L. Femtosecond-assisted arcuate keratotomy for the correction of postkeratoplasty astigmatism: vector analysis and accuracy of laser incisions. Cornea. 2015;34:1063-6.

29. Fadlallah A, Mehanna C, Saragoussi JJ, et al. Safety and efficacy of femtosecond laser-assisted arcuate keratotomy to treat irregular astigmatism after penetrating keratoplasty. J Cataract Refract Surg. 2015;41: 1168-75.

30. anNakhli F, Khattak A. Vector analysis of femtosecond laser-assisted astigmatic keratotomy after deep anterior lamellar keratoplasty and penetrating keratoplasty. Int Ophthalmol. 2019;39:189-98.

31. Kim BK, Mun SJ, Lee DG, et al. Clinical outcomes of beveled, full thickness astigmatic keratotomy. J Korean Ophthalmol Soc. 2015;56:1160-9.

\section{Publisher's Note}

Springer Nature remains neutral with regard to jurisdictional claims in published maps and institutional affiliations.

Ready to submit your research? Choose BMC and benefit from:

- fast, convenient online submission

- thorough peer review by experienced researchers in your field

- rapid publication on acceptance

- support for research data, including large and complex data types

- gold Open Access which fosters wider collaboration and increased citations

- maximum visibility for your research: over $100 \mathrm{M}$ website views per year

At $\mathrm{BMC}$, research is always in progress.

Learn more biomedcentral.com/submissions 